Chaire de recherche sur les enjeux économiques intergénérationnels

\title{
Income Volatility, Health and Well-Being
}

Amélie Adeline, Ismaël Choinière Crèvecoeur,

Raquel Fonseca and Pierre-Carl Michaud

Cahier de recherche Working paper

Décembre / December 2019

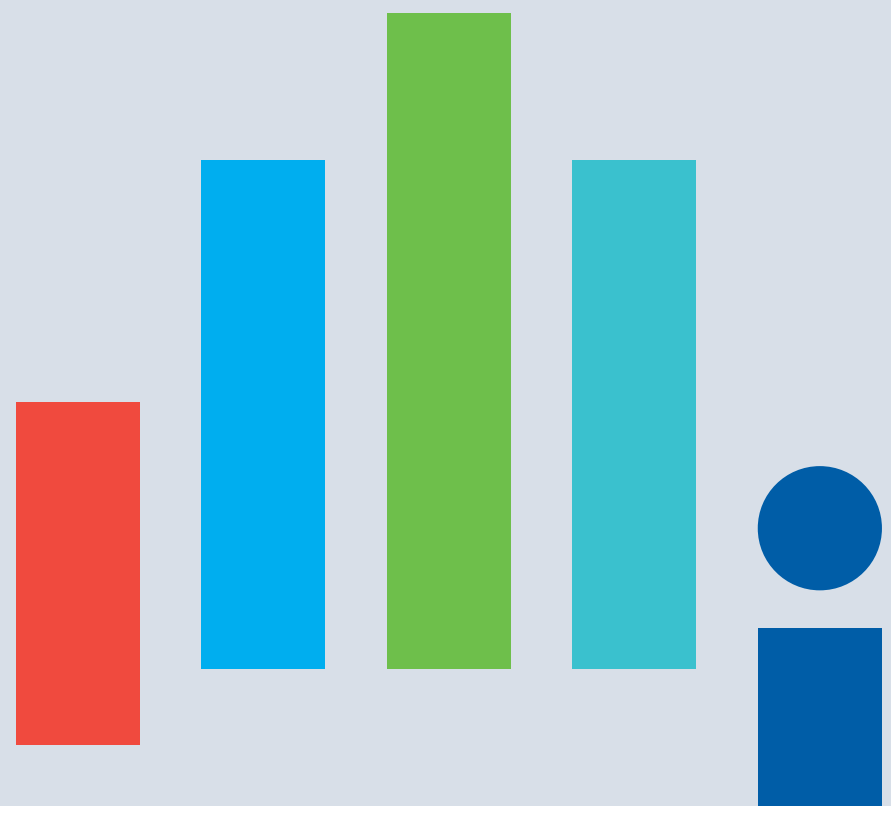




\title{
Chaire de recherche
} sur les enjeux économiques intergénérationnels

\author{
est une chaire multi-institutionnelle qui s'appuie
}

sur un partenariat avec les organisations suivantes :

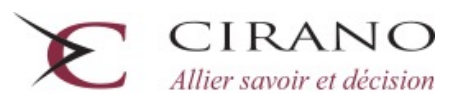

Quetraite

Les opinions et analyses contenues dans les cahiers de recherche de la Chaire ne peuvent en aucun cas être attribuées aux partenaires ni à la Chaire elle-même et elles n'engagent que leurs auteurs.

Opinions and analyses contained in the Chair's working papers cannot be attributed to the Chair or its partners and are the sole responsibility of the authors. 


\title{
Income Volatility, Health and Well-Being
}

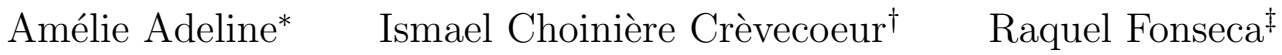 \\ Pierre-Carl Michaud ${ }^{\text {II }}$
}

December 3, 2019

\begin{abstract}
While there is mounting evidence that large income shocks, e.g. in the form of a job loss, may impact health and mortality, little evidence exist on the potential relationship between sustained income volatility, keeping average lifetime income constant, and health. This paper exploits rich survey data on the near-elderly in Canada paired with their administrative tax records to investigate whether a relationship exists between health and well-being on the one hand, and individual-specific volatility of income on the other, decomposing volatility into a permanent and transitory component. Controlling for average lifetime income, we find that a one unit increase in the standard deviation of the permanent component of $(\log )$ income experienced over the working life is associated with a lower probability of being in excellent $(-23.9 \%)$ and very good health $(-13.3 \%)$, to be satisfied with life $(-34.9 \%)$, and implies the onset of 1.1 additional mental health issues. Similar results, albeit smaller in size, are found for the transitory component of income. These results have potentially important implications for public policy, as well as, understanding the relationship between the labor market and population health.
\end{abstract}

Keywords: Income volatility, health, well-being, Canada

JEL Codes: C22; D31; I10; I14; I31

*THEMA, University of Cergy-Pontoise. Email: amelie.adeline@yahoo.fr

${ }^{\dagger}$ ESG UQAM and CREEi. Email: ismael.crevecoeur@gmail.com

${ }^{\ddagger}$ ESG UQAM and CIRANO. Email: fonseca.raquel@uqam.ca

${ }^{\S}$ HEC Montreal, NBER and CIRANO. Email: pierre-carl.michaud@hec.ca

ฯThis research is also part of the program of the Research Chair in Intergenerational Economics. We are grateful to the Quebec Inter-university Center for Social Statistics (QICSS) which gives us access to the data used in this research. We are also thankful to F. Langot and A. Guay for their advice and comments. All errors are our own. 


\section{Introduction}

Over time and space, a strong correlation has been documented between socio-economic status (SES), in particular income, and health (Winkleby et al., 1992; Smith, 1999; Case et al., 2002; Deaton, 2008). Understanding the sources of this health-SES gradient has been at the forefront of the research agenda in health economics for the last decades. As documented by Smith (2007), the gradient expands over the working years to fade once individuals reach retirement. Hence, some of its origins may steem from experience on the labor market.

There is mounting evidence that labor market shocks, such as job loss, may impact health, sometimes later in life. In the United States, Strully (2009), Sullivan \& Von Wachter (2009), Michaud et al. (2016), and Schaller \& Stevens (2015), all find a negative effect of job loss on health and well-being outcomes. For example, Sullivan \& Von Wachter (2009) show that there is a 10-15\% increase in mortality rates for displaced workers 20 years after the job displacement when compared to other workers. A link between job loss and biomarkers has been found in Michaud et al. (2016), who used the Health and Retirement Study. General well-being also appears to suffer following events such as unemployment (Winkelmann \& Winkelmann, 1998).

Yet, Smith (2007) finds modest evidence that dynamics in income predict health events during the working life. While using noisy measures of income from survey data could explain this weak result, there is also the possibility that the impact of labor market turmoil may take time to materialize. In fact, some biological theories emphasize the potential negative health effects of the cumulative toll from stress related to shocks in various domains of life, including the labor market (Seeman et al., 1997). This cumulative toll has often be referred too as the allostatic load. Just like any machinery, the human body experiences more rapid wear and tear when its capacity to adapt is challenged repeatedly.

The theory of allostatic load would predict workers with higher volatility may experience more stress and therefore carry a larger allostatic load, which could lead to adverse health effects in later life. While the theory is plausible, and could explain why the gradient expands 
over the working years, we know of no empirical test looking for associations between volatility over worker's careers and health at older ages.

In this paper, we investigate the impacts of income volatility (both permanent and transitory volatility) experienced over the working life on health and well-being after 50 years old. We use health and well-being information from the 2012, 2014 and 2016 waves of the Longitudinal and International Study of Adults (LISA) for respondents over the age of 50, and we estimate individual level income volatility measures by applying the methodology developed by Carroll \& Samwick (1997) on Canadian administrative tax records associated to each respondent from 1981 to 2015 (34 years). We then relate the two in a regression framework which controls for various confounders, and importantly, for lifetime average income.

Our results support the view that volatility over the life-cycle is associated with worse health and well-being. Controlling for the average level of income during the working life, we find evidence that permanent and transitory income risks are negatively associated with health and well-being. Indeed, a one unit increase in the variance of the permanent component of income experienced over the working life is associated with a decrease in the probabilities to be in excellent and very good health by $23.9 \%$ and $13.3 \%$ respectively, a decrease in the probability to be satisfied with life by $34.9 \%$, and implies the onset of 1.1 additional mental health issues. Moreover, a one unit increase in the variance of the transitory component of income is associated with a decrease in the probabilities to be in excellent and very good health by $5.74 \%$ and $3.20 \%$ respectively; a decrease in the probability to be satisfied with life by $11.95 \%$, and implies the onset of 0.42 additional mental health issues. One particular threat to our identification strategy is that health shocks during the working life caused volatility in income. In order to control for this issue, we show that results are very similar whether or not we exclude those who may have received disability benefits during the 34 years covered by the data.

Our analysis is structured as follows. Section 2 details the two databases used to carry out the analysis and gives some descriptive statistics. Section 3 presents the method used to compute measures of volatility, as well as, the econometric analysis. In section 4 , we give an 
interpretation of our results. Section 5 concludes the paper.

\section{Data and descriptive statistics}

To conduct our analysis, we use the Longitudinal and International Study of Adults (LISA), a multidisciplinary and unique database of micro data on health, life satisfaction, education, employment, income, and family of individuals from Canada. Since 2012, LISA asks questions to a sample of households throughout Canada, these households being re-interviewed every two years in the panel.

We also use the retrospective component of LISA database based on administrative data sources. Indeed, LISA is linked to the "T1 Family File" corresponding to annual tax records for census families and individuals ${ }^{1}$, and to the "T4 Summary and Supplementary Files". The latter gives access to individuals' income history, to information on whether individuals are eligible and used different tax credits, and on their marital status, from 1981 to 2015.

\subsection{Sample selection}

To properly identify the relationship between income volatility, and, health and well-being, we focus on a population of men aged 50 to 75 in 2012, 2014 and 2016, since this corresponds to a period in which health generally begins to deteriorate. We focus our analysis on individuals who were surveyed at least once in the three waves of this survey. When they have been interviewed more than once, we focus on their answers in the most recent wave.

To estimate income volatility, we focus on income history of these respondents while they were between 30 and 55 years old between 1981 and 2015. We restrict our sample to respondents aged 30 to 55 since such an age range corresponds to a working-age period in which individuals are no longer at school and are not yet retired. We choose to work on a male population as they are less likely to make voluntary exits from the labor force, for example, due to childbearing which could also have health consequences. Since information

\footnotetext{
${ }^{1}$ These data give information on demographic characteristics and income, collected from income tax returns submitted to the Canada Revenue Agency (CRA).
} 
on income history are available from 1981 to 2015, we exclude respondents over 75 years old in 2012, 2014 and 2016 to ensure sufficient information concerning income history. Indeed, the more aged are the individuals considered in the 2012-2016 sample, the less available information we have to compute income variances, given that the latter are computed during the working-age (from 30 to 55 years old). ${ }^{2}$

Table 1 gives details about the different sample restrictions. We end up with a sample of 5,134 respondents over the three waves.

\begin{tabular}{ll}
\hline (1) Total Individuals & 27,712 \\
(2) Men & 13,434 \\
(3) 50-75 years old & 5,416 \\
(4) Available information on current income on tax records & 5,134 \\
\hline
\end{tabular}

Table 1: Sample selection - LISA database: Starting from the original LISA sample (1), we restrict to a sample of men (2) and then select only respondent aged between 50 and 75 years old (3). We also drop respondents for whom we have missing information on their annual income between 1981 and 2015 (4).

\subsection{Health and well-being outcomes}

We now define the different health and well-being variables: self-perceived health status, life satisfaction and mental health.

Self-perceived health status assesses the general perceived health of an individual. Respondents are asked: "Would you say your health in general is..." and they have to choose between five answers: "excellent", "very good", "good", "fair" or "poor". Self-perceived health status is an important subjective predictor of an individual's health since it combines different elements that an individual knows about his own health and integrates factors which are not always considered by health professionals such as individuals' beliefs and attitudes towards health commodities (Benitez-Silva et al. (2004)).

\footnotetext{
${ }^{2}$ For instance, an individual who is 86 years old in 2012 in the well-being sample, was 55 years old in 1981, such that we only have a single observation to compute his income variances given the selection criteria (income variances computed during the working age). The white part of Table 7 in the appendix section B represents the information set for respondents aged between 50 and 75 years old in 2012 (final health and well-being sample), which can be used to compute variances of income (the latter being computed during the working age).
} 
We also consider an indicator on satisfaction individuals have with their life, to investigate well-being. Individuals are asked to rate their feelings about life in general, from very unsatisfied (0), to very satisfied (10). We create a dummy equal to one when the individual rates his feeling about life from 7 to 10, or in other words, when the individual seems satisfied with his life in general. ${ }^{3}$

Moreover, LISA asks individuals a set of ten questions on their feelings concerning their mental health such as "In the last month, how often did you feel anxious" or "In the last month, how often did you feel sad/depressed", for which individuals respond by "never", "rarely", "sometime", "most of the time", or "all the time", (see Appendix section A for further details). We create a dummy variable equal to one when individuals respond "sometime", "most of the time" or "all the time". Then, we create a variable which adds up each issue reported by an individual. Thus, we consider this variable as a sum of these different problems which ranges from 0 to 10 .

Figure 1 presents descriptive statistics on the different outcome variables. A majority of respondents rate their self-assessed health as good and very good. Over $80 \%$ of them rate life satisfaction at a level of 7 and above meaning that the majority of individuals seems satisfied with their life. Finally, about $20 \%$ of individuals report having at least one mental health issue in the last month. Figure 2 presents the distribution of specific mental health issues, used to construct our mental health index. About $24 \%$ and $17 \%$ of the respondents report feeling tired out for no good reason, and, restless or unable to stand still, respectively. Close to $16 \%$ of the respondents declare feeling nervous. More than $10 \%$ report feeling either depressed, or, that everything is an effort. Finally, around 5\% reveal feeling desperate; worthless; so nervous that nothing could calm them down; so restless that they could not stand still; or, so depressed that nothing could cheer them up.

\footnotetext{
${ }^{3}$ Using the score without transformation results found are similar and available upon request.
} 

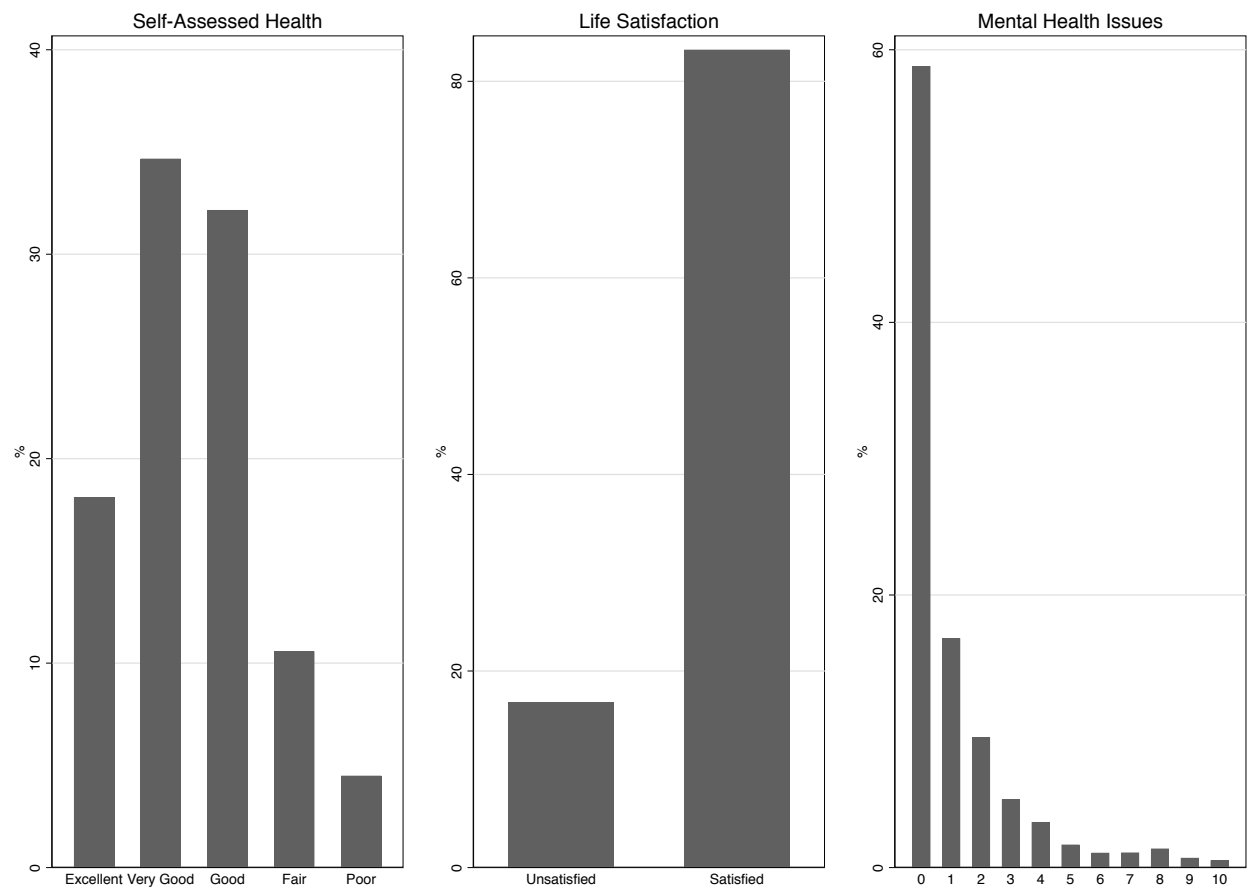

Figure 1: Distribition of health and well-being outcomes

\subsection{Retrospective component of LISA}

To measure income volatility, we use the variance of residual income. To decompose the variance of income into permanent and transitory dimensions, we use information obtained in the retrospective component of the data from 1981 to 2015 . We focus on total family income before taxes, which includes the taxfiler's income from taxable, as well as, nontaxable sources. Using family income instead of personal income gives more information about the financial situation of the respondents because it allows to account for the insurance effects between household members. ${ }^{4}$ Income is then deflated using the Consumer Price Index with 2013 as the base year.

Some individuals report having a very low income which might be equal to zero sometimes.

\footnotetext{
${ }^{4}$ Using personal income of the respondent might be misleading due to an overestimation of the variances of income whenever a respondent has an unstable income situation and lives with someone who might have a stable financial situation. On the other hand, we might underestimate the variances of income when considering an individual who has a stable income situation but lives with someone who is financially unstable. Thus, we also control for the fact of being in a relationship in the tendency (being married or in a common law).
} 


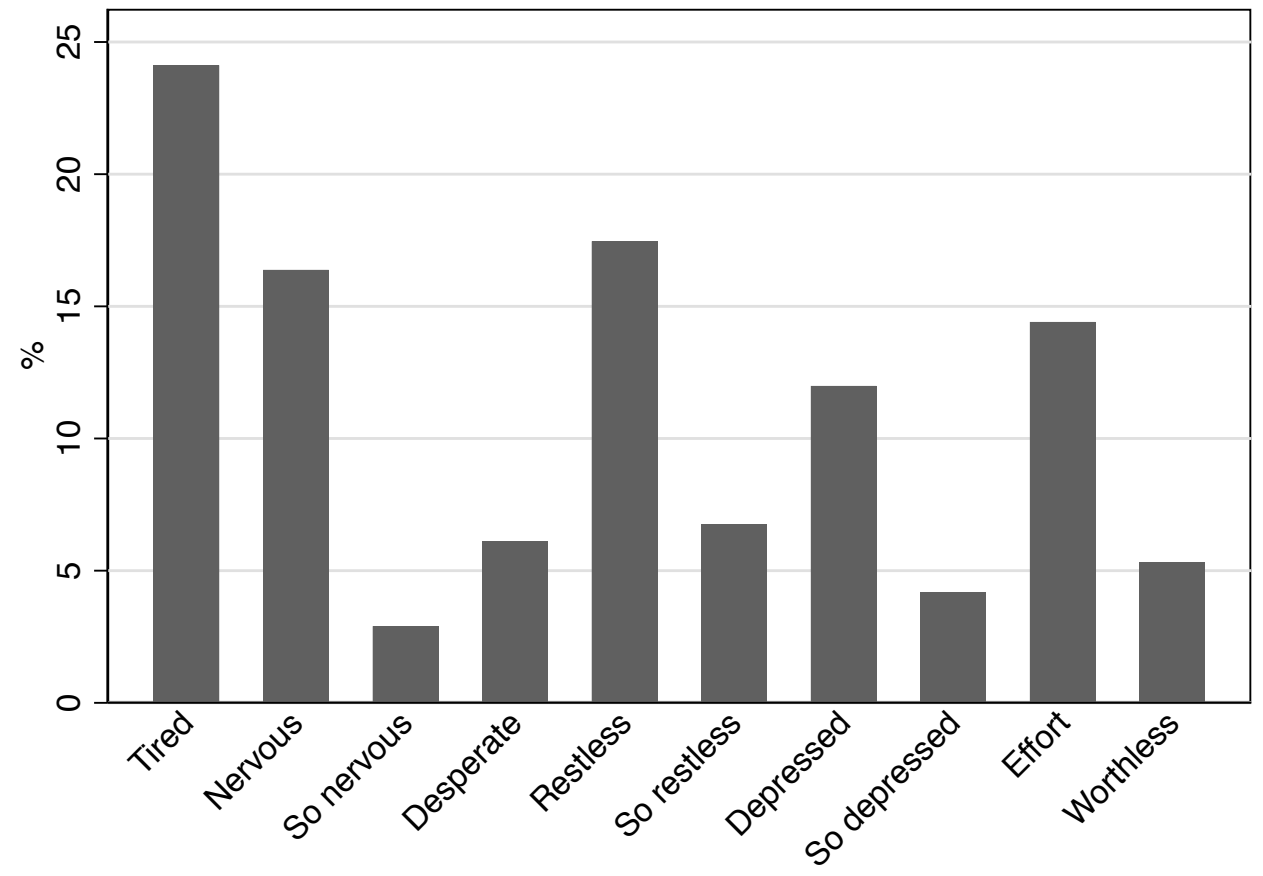

Figure 2: Mental health issues: "Tired" refers to tired out for no good reason. "So nervous" refers to "so nervous that nothing could calm down". "Restless" refers to restless or be unable to stand still. "So restless" refers to "so restless that could not stand still". "Depressed" refers to sad/depressed. "So depressed" refers to "so depressed that nothing could cheer the individual up". "Effort" refers to "everything was an effort". "Worthless" refers to the feeling of being "good for nothing".

However, individuals can apply for a welfare aid program representing a few thousand dollars a year. Moreover, individuals reporting zero income may have worked abroad during this period. To address this concern, we exclude individuals who report $\$ 0$ for income. Then, for the other incomes below $\$ 11,000$, we impose the latter to take this upper limit as a minimum. ${ }^{5}$ Finally, for individuals who claimed to be retired, we exclude their income observations in the years following the year they retired.

\footnotetext{
${ }^{5}$ We choose this amount since it corresponds to the 2013 non-refundable tax credit, also known as the personal amount, and adjusted annually to allow for inflation.
} 


\subsection{Covariates}

We also use a set of covariates when estimating effects of permanent and transitory income risk on health and well-being. As a result, we include categories for age and education, the civil status, the number of children, the fact of being born in Canada, and in order to capture regional effects, dummies for provinces of Canada. ${ }^{6}$

\section{Econometric analysis}

We first present the methodology used to estimate the variances of the permanent and transitory components of income in order to identify the income risks experienced by each respondent during their working life. Next, we detail the methodology used to analyze the association between income risk on one hand and health and well-being on the other.

\subsection{Estimating variances of transitory and permanent shocks}

Estimation of the variances of permanent and transitory shocks follows the methodology proposed by Carroll \& Samwick (1997). Two steps are involved. ${ }^{7}$ First, we are interested in residual income volatility once predictable changes in income are accounted for. Hence, the predictable growth needs to be removed from the income process. In a second step, we compute a specific time series estimation of the variance of transitory and permanent components which come from unexpected events for each respondent.

Our approach to estimate income volatility differs from Carroll \& Samwick (1997) in two ways. First, we use administrative data which comes from income tax returns in Canada, while they use U.S. survey data from the Panel Study of Income Dynamics. The advantage of administrative data is to reduce potential for measurement errors which biased income volatility (Bound et al. (2001) explain that measurement errors might be prevalent in survey

\footnotetext{
${ }^{6}$ Descriptive statistics on these variables are not included here but available upon request.

${ }^{7}$ Meghir \& Pistaferri (2004) also use this method to investigate dynamics of the variance of income and the associated observable and unobservable heterogeneity using an ARCH process on the Panel Study of Income Dynamics. They look at the impact of income shocks early in life on earnings determination.
} 
data). Second, our observation window and selected sample give access up to 26 observations per respondent, while Carroll \& Samwick (1997) only use 7 observations per individual. ${ }^{8}$

We model $(\log )$ income, $\log y_{i t}$, as the product of a predictable component, $p_{i t}$, a permanent shock (random walk), $\eta_{i t}$, and a transitory component, $\epsilon_{i t}$, which is iid with variance $\sigma_{i, \epsilon}^{2}$ (individual specific). Denote (log) income as:

$$
\log y_{i t}=p_{i t}+\eta_{i t}+\epsilon_{i t}
$$

The predictable component is given by $p_{i t}=x_{i t} \gamma$. We allow for heterogeneity between respondents growth path by allowing $\gamma$ to vary by provinces (Atlantic, Quebec, Ontario, Prairies and British Columbia) and levels of education (less than high school and high school, college, university). We include in $x_{i t}$ a quadratic age and marital status (single or couple). In order to have robust results, we also control for health status in a robustness test since it can affect the ability to work and thus income. To do so, we include in $x_{i t}$ a dummy if the respondent receives a tax benefit for being disabled. ${ }^{9}$ We thus create a binary variable equal to one when an individual states having received this help. ${ }^{10}$ Denoting $\nu_{i t}=\eta_{i t}+\epsilon_{i t}$, we first net out the predictable component by estimating $\gamma$ by OLS from $\log y_{i t}=x_{i t} \gamma+\nu_{i t}$ (for each province and education group pair). We then obtain the residuals $\nu_{i t}$ from this regression. These residuals are used in the second step.

We model the permanent component of income as a random walk, $\eta_{i t}=\eta_{i, t-1}+\zeta_{i t}$ where

\footnotetext{
${ }^{8}$ Indeed, we have access to information on respondents aged between 30 and 55 from 1981 to 2015, while Carroll \& Samwick (1997) have access to data only from 1981 to 1987.

${ }^{9}$ The variable is defined as follows: "A taxfiler may claim a preset disability amount if he or she was severely physically or mentally impaired in the tax year, and the impairment noticeably restricted the taxfiler's activities of daily living."

${ }^{10}$ Available since 1982, this disability indicator is only used in order to compute the variances of income because it allows to purge the variances from health effects. As a result, when using these variances, we ensure the exogeneity of the latter in the health and well being estimates.
} 
$\zeta_{i t}$ is iid with variance $\sigma_{i \zeta}^{2}$. We then define the difference in residuals between $d$ years as:

$$
\begin{aligned}
r_{i d} & =\nu_{i t+d}-\nu_{i t} \\
& =\eta_{i t+d}+\epsilon_{i t+d}-\eta_{i t}-\epsilon_{i t},
\end{aligned}
$$

Recursively substituting we obtain:

$$
r_{i d}=\left(\zeta_{i t+1}+\zeta_{i t+2}+\ldots+\zeta_{i t+d}\right)+\epsilon_{i t+d}-\epsilon_{i t}
$$

which is a function of $d$ permanent shocks and 2 transitory shocks. The variance of equation (4) is given by:

$$
r_{i d}^{2}=\operatorname{Var}\left(r_{i d}\right)=d \sigma_{i \zeta}^{2}+2 \sigma_{i \epsilon}^{2}
$$

For each respondent, we construct the set of all possible $r_{i d}^{2}$ (for each pairwise combination of residuals), which is a function of $d$ and the constant 2 , to estimate $\sigma_{i \zeta}^{2}$ and $\sigma_{i \epsilon}^{2}{ }^{11}$ The latter are obtained by running, for each individual $i$, a regression of $r_{i d}^{2}$ on $d$, and 2 , a constant term for all $d$. We allow for serial correlation in $\epsilon_{i t}$, in the form of a moving average of order 2 process, by exploiting only pairwise comparisons of order $d>2 .{ }^{12}$

Table 2 shows means across respondents of the variances of permanent and transitory components. We see that estimated variances of the permanent component of income are quite low with an average of 0.0261 , while variances of the transitory component of income are higher with an average of $0.0994 .^{13}$

Table 3 shows OLS estimates of these variances on the different covariates used in the health and well-being estimates, i.e. (i) the logarithm of the average income when individuals are between 30 and 55 years old, (ii) the birth year of individuals, (iii) the marital status in

\footnotetext{
${ }^{11}$ Indeed, equation 5 corresponds to $d$ times the variance of the permanent component of income and 2 times the variance of the transitory component of income.

${ }^{12}$ As discussed by Carroll \& Samwick (1997), studies in the literature do not find evidence of household income process with transitory component of order greater than $M A(2)$ (see MaCurdy (1982), Abowd \& Card (1989) and Moffitt \& Gottschalk (2011)).

${ }^{13}$ The fact that the average variance of the permanent component of income is smaller than the transitory one does not indicate that the former contributes less to the total variance. Given the permanent shock is a random walk, the variance of a permanent shock $T$ periods ahead is $T \sigma_{i, \zeta}^{2}$.
} 


\begin{tabular}{rcc}
\hline & Permanent & Transitory \\
\hline Mean & 0.0261 & 0.0994 \\
Standard deviation & 0.0841 & 0.2996 \\
\hline
\end{tabular}

Table 2: Variances of permanent and transitory components of income

2012-2016, (iv) the levels of education, (v) the provinces in which an individual lives, (vi) the fact of being born in Canada or not, and (vii) the number of children. On one hand, results suggest that variances of the permanent component of income are positively and significantly correlated with the birth year, the levels of education, the provinces and the number of children. On the other hand, a positive relationship is found with the provinces and the fact of being born in Canada for the variances of the transitory component of income. As a result, living in British Columbia, relatively to the Atlantic provinces is significantly correlated with a higher variance of both permanent and transitory components of income. On the contrary, being born in Canada is negatively related to the variance of the permanent component of income. Moreover, the variance of the transitory component of income is negatively correlated to the marital status, and the number of children. Finally, the average level of income is negatively related to the variances of both permanent and transitory components.

\subsection{Estimating impacts of income risk on health and well-being}

We use these estimates to investigate the association of permanent and transitory income volatility occurring during the working life (from 30 to 55 years old) on self-perceived health status, life-satisfaction and mental health in older ages (from 50 to 75 years old, in 2012-2016). We estimate the following equation:

$$
h_{i}=\beta_{0}+\beta_{1} \sigma_{i \zeta}^{2}+\beta_{2} \sigma_{i \epsilon}^{2}+\beta_{3} \log \bar{y}_{i}+X_{i} \Gamma+u_{i}
$$

where $h_{i}$ corresponds to the health or well-being outcome of individual $i ; \sigma_{i \zeta}^{2}$ corresponds to the variance of the permanent component of income; $\sigma_{i \epsilon}^{2}$ corresponds to the variance of the transitory one; $\log \bar{y}_{i}$ is the logarithmic transformation of average income of individual 


\begin{tabular}{|c|c|c|}
\hline & \multicolumn{2}{|c|}{ Income risk } \\
\hline & Permanent & Transitory \\
\hline $\log \bar{y}_{i}$ & $\begin{array}{c}-0.0045 * * * \\
(0.0017)\end{array}$ & $\begin{array}{c}-0.0499 * * * \\
(0.0052)\end{array}$ \\
\hline $1940-1944$ & $\begin{array}{l}-0.0028 \\
(0.0056)\end{array}$ & $\begin{array}{c}0.0042 \\
(0.0170)\end{array}$ \\
\hline $1945-1949$ & $\begin{array}{c}0.0011 \\
(0.0051)\end{array}$ & $\begin{array}{c}0.0017 \\
(0.0156)\end{array}$ \\
\hline $1950-1954$ & $\begin{array}{l}-0.0032 \\
(0.0050)\end{array}$ & $\begin{array}{c}0.0145 \\
(0.0153)\end{array}$ \\
\hline $1955-1959$ & $\begin{array}{l}-0.0027 \\
(0.0050)\end{array}$ & $\begin{array}{c}0.0195 \\
(0.0151)\end{array}$ \\
\hline $1960-1964$ & $\begin{array}{c}0.0040 \\
(0.0050)\end{array}$ & $\begin{array}{c}0.0020 \\
(0.0153)\end{array}$ \\
\hline $1965-1969$ & $\begin{array}{c}0.0114 * * \\
(0.0058)\end{array}$ & $\begin{array}{l}-0.0248 \\
(0.0177)\end{array}$ \\
\hline Marital status & $\begin{array}{l}-0.0027 \\
(0.0024)\end{array}$ & $\begin{array}{c}-0.0212 \text { *** } \\
(0.0074)\end{array}$ \\
\hline High School & $\begin{array}{l}-0.0028 \\
(0.0024)\end{array}$ & $\begin{array}{l}-0.0009 \\
(0.0073)\end{array}$ \\
\hline College & $\begin{array}{l}-0.0021 \\
(0.0028)\end{array}$ & $\begin{array}{c}0.0047 \\
(0.0084)\end{array}$ \\
\hline University & $\begin{array}{c}0.0083 * * * \\
(0.0028)\end{array}$ & $\begin{array}{c}0.0097 \\
(0.0087)\end{array}$ \\
\hline Quebec & $\begin{array}{c}0.0031 \\
(0.0024)\end{array}$ & $\begin{array}{c}0.0006 \\
(0.0073)\end{array}$ \\
\hline Ontario & $\begin{array}{c}0.0018 \\
(0.0025)\end{array}$ & $\begin{array}{c}0.0236 * * * \\
(0.0076)\end{array}$ \\
\hline Prairies & $\begin{array}{c}0.0062 * * * \\
(0.0024)\end{array}$ & $\begin{array}{c}0.0117 \\
(0.0072)\end{array}$ \\
\hline British Columbia & $\begin{array}{l}0.0054 * \\
(0.0030)\end{array}$ & $\begin{array}{c}0.0284 * * * \\
(0.0090)\end{array}$ \\
\hline Born in Canada & $\begin{array}{c}-0.0391 * * * \\
(0.0022)\end{array}$ & $\begin{array}{c}0.0442 * * * \\
(0.0067)\end{array}$ \\
\hline Number of children & $\begin{array}{c}0.0024 * * \\
(0.0010)\end{array}$ & $\begin{array}{c}-0.0067 * * \\
(0.0030)\end{array}$ \\
\hline cons & $\begin{array}{c}0.0710 * * * \\
(0.0084)\end{array}$ & $\begin{array}{c}0.2607 * * * \\
(0.0256)\end{array}$ \\
\hline $\mathrm{N}$ & 4,890 & 4,890 \\
\hline
\end{tabular}

Table 3: Estimates of the variances of permanent and transitory components of income: standard errors are into parentheses. $* * *$ : statistically significant at $1 \%$; **: statistically significant at $5 \%$; : statistically significant at $10 \%$. 
$i$ when the individual was between 30 and 55 years old; $X_{i}$ stands for variables of control (socio-demographic characteristics of individual $i$ ) and $u_{i}$ is an error term assumed to be normally distributed.

Concerning self-assessed health, it corresponds to a qualitative dependent variable. We observe an indicator of the category such that the observed variable is equal to $1,2,3,4$ or 5 for "excellent", "very good", "good", "fair" or "poor" respectively. Thus, we estimate the following equation with an ordered probit model:

$$
h_{i}^{*}=\beta_{0}+\beta_{1} \sigma_{\zeta, i}^{2}+\beta_{2} \sigma_{\epsilon, i}^{2}+\beta_{3} \log \bar{y}_{i}+X_{i} \Gamma+u_{i}
$$

where $h_{i}^{*}$ is a latent variable which underlies self-reported health status.

Next, we investigate a more general definition of well-being with life satisfaction. For this outcome, we estimate equation 7 with a probit, where $h_{i}^{*}$ is a latent variable which underlies life satisfaction. Finally, LISA database contains detailed information on mental health such that we investigate the impact of income risk on a sum of mental health issues using an OLS model.

We study the impact of income risk on a broad range of health and well-being outcomes to get a relatively complete picture of the relationship between income volatility during a working-age period and health and well-being of individuals aged 50 and older. For each outcome, we run two specifications where covariates are added one by one: (1) only variances of the permanent and transitory components of income; (2) plus logarithm of the average income between 30 and 55 years old ${ }^{14}$, and demographic variables (groups of age, being in a relationship, categories of education, dummies for provinces of Canada, number of children and a dummy equal to one when the individual is born in Canada).

\footnotetext{
${ }^{14}$ Estimates controlling for the square of the logarithm of average income have been implemented as a robustness check. Results are very similar and available upon request.
} 


\section{Results}

\subsection{General results}

We focus on the impact of income volatility on three outcomes: self-assessed health, life satisfaction and mental health. In Table 4, we report strong associations of both transitory and permanent components of income with our outcomes. Column (1) represents the estimates without the covariates and the logarithmic transformation of the average income and covariates. Results across columns are very similar such that we focus our analyses on the last column.

The variance of the permanent component of income has a global negative association with the different outcomes studied (see coefficients of $\sigma_{\zeta}^{2}$ in column (2) of Table 4). Indeed, a one unit increase in the variance of the permanent component of income experienced over the working life decreases the probabilities to be in excellent and very good health by $23.86 \%$ and $13.31 \%$ respectively, and decreases the probability to be satisfied with life by $34.95 \%$. Furthermore, our estimates suggest that the variance of the permanent component of income is associated with a change of the onset of 1.1 additional mental health issues. More specifically, the variance of the permanent component of income has a negative association with feeling so nervous that nothing could calm down, depressed and worthless (see coefficients $\sigma_{\zeta}^{2}$ in Table 5).

Moreover, the variance of the transitory component of income has a global negative as-

sociation with each outcome (see the coefficients of $\sigma_{\epsilon}^{2}$ in column (2) of Table 4). For all these outcomes, the associations are smaller than the associations of the variance of the permanent component of income. Indeed, a one unit increase in the variance of the transitory component of income is associated with a decrease of the probabilities to be in excellent and very good health by $5.74 \%$ and $3.20 \%$ respectively, and it is associated with a decrease of the probability to be satisfied with life by $11.95 \%$. Concerning mental health, a one unit increase in the variance of the transitory component of income is associated with an increase of 0.42 in the number of mental health issues. More specifically, we investigate this last relationship 
by studying the association of these variances on each mental health outcomes (see Table 5). According to these results, the negative relationship between the mental health indicator and the variance of the transitory component of income comes from the following mental health issues: feeling nervous and so nervous that nothing could calm down, and depressed. Particularly, a one unit increase in the variance of the transitory component of income is associated with an increase of around $7 \%$ in the probability to report being nervous or depressed. In other words, events such as a job loss, group or individual layoffs or business closures, have negative associations with mental health issues.

Finally, in the second column of Table 4, we investigate the association of the logarithmic transformation of the average income, while the individuals were between 30 and 55 years old. Indeed, we focus on income volatility such that we should also control for the average income level in order to capture the real impact of the variances of income. For each outcome, results suggest a positive association of average income with health and well-being. Indeed, looking at self-assessed health, a $1 \%$ increase of the average income during the working life is associated with an increase in the probabilities to report being in excellent and very good health of $8.17 \%$ and $4.56 \%$ respectively. For life satisfaction, a $1 \%$ increase of the average income during the working life is associated with an increase in the probability to be satisfied with life of $8.16 \%$. For mental health, a $1 \%$ increase of the average income during the working life is associated with a decrease of 0.51 mental health issues. Moreover, focusing on each mental health outcomes (Table 5), we see that a $1 \%$ increase of the average income during the working life is associated with a significant decrease of the probability of the onset of each mental health issues. 


\begin{tabular}{|c|c|c|c|c|}
\hline & & & $(1)$ & $(2)$ \\
\hline \multirow[t]{17}{*}{ Self-assessed health } & $\sigma_{\zeta}^{2}$ & Excellent & $\begin{array}{c}-0.2703^{* * *} \\
(0.0774)\end{array}$ & $\begin{array}{c}-0.2386^{* * *} \\
(0.0787)\end{array}$ \\
\hline & & Very good & $\begin{array}{c}-0.1518^{* * *} \\
(0.0435)\end{array}$ & $\begin{array}{r}-0.1331^{* * *} \\
(0.0440)\end{array}$ \\
\hline & & Good & $\begin{array}{c}0.1810^{* * *} \\
(0.0519)\end{array}$ & $\begin{array}{c}0.1592^{* * *} \\
(0.0526)\end{array}$ \\
\hline & & Fair & $\begin{array}{c}0.1472^{* * *} \\
(0.0423)\end{array}$ & $\begin{array}{c}0.1317^{* * *} \\
(0.0436)\end{array}$ \\
\hline & & Poor & $\begin{array}{c}0.0940^{* * *} \\
(0.0273)\end{array}$ & $\begin{array}{c}0.0808^{* * *} \\
(0.0270)\end{array}$ \\
\hline & $\sigma_{\epsilon}^{2}$ & Excellent & $\begin{array}{c}-0.1237^{* *} \\
(0.0262)\end{array}$ & $\begin{array}{c}-0.0574^{* *} \\
(0.0258)\end{array}$ \\
\hline & & Very good & $\begin{array}{c}-0.0695^{* *} \\
(0.0148)\end{array}$ & $\begin{array}{c}-0.0320^{* *} \\
(0.0144)\end{array}$ \\
\hline & & Good & $\begin{array}{c}0.0828^{* *} \\
(0.0176)\end{array}$ & $\begin{array}{c}0.0383^{* *} \\
(0.0172)\end{array}$ \\
\hline & & Fair & $\begin{array}{c}0.0673^{* *} \\
(0.0144)\end{array}$ & $\begin{array}{c}0.0317^{* *} \\
(0.0143)\end{array}$ \\
\hline & & Poor & $\begin{array}{c}0.0430^{* *} \\
(0.0094)\end{array}$ & $\begin{array}{c}0.0194^{* *} \\
(0.0088)\end{array}$ \\
\hline & $\ln ($ Income $)$ & Excellent & & $\begin{array}{c}0.0817^{* * *} \\
(0.0082)\end{array}$ \\
\hline & & Very good & & $\begin{array}{c}0.0456^{* * *} \\
(0.0047)\end{array}$ \\
\hline & & Good & & $\begin{array}{c}-0.0546^{* * *} \\
(0.0055)\end{array}$ \\
\hline & & Fair & & $\begin{array}{c}-0.0451^{* * *} \\
(0.0047)\end{array}$ \\
\hline & & Poor & & $\begin{array}{c}-0.0277^{* * *} \\
(0.0032)\end{array}$ \\
\hline & & $\mathbf{N}$ & 4,890 & 4,890 \\
\hline & Covariates & Demographic & No & Yes \\
\hline
\end{tabular}

Table 4: Effect of income volatility on health and well-being: $\sigma_{\zeta}^{2}$ refers to the variance of the permanent component of income, while $\sigma_{\epsilon}^{2}$ refers to the one of the transitory component of income. Marginal effects are reported, with standard errors into parentheses. ***: statistically significant at $1 \%$;** statistically significant at 5\%; *: statistically significant at $10 \%$. Demographic variables are categories of age and education, marital status, number of children, being born in Canada and categories for provinces. Self-assessed health is clustered at the respondent level. 


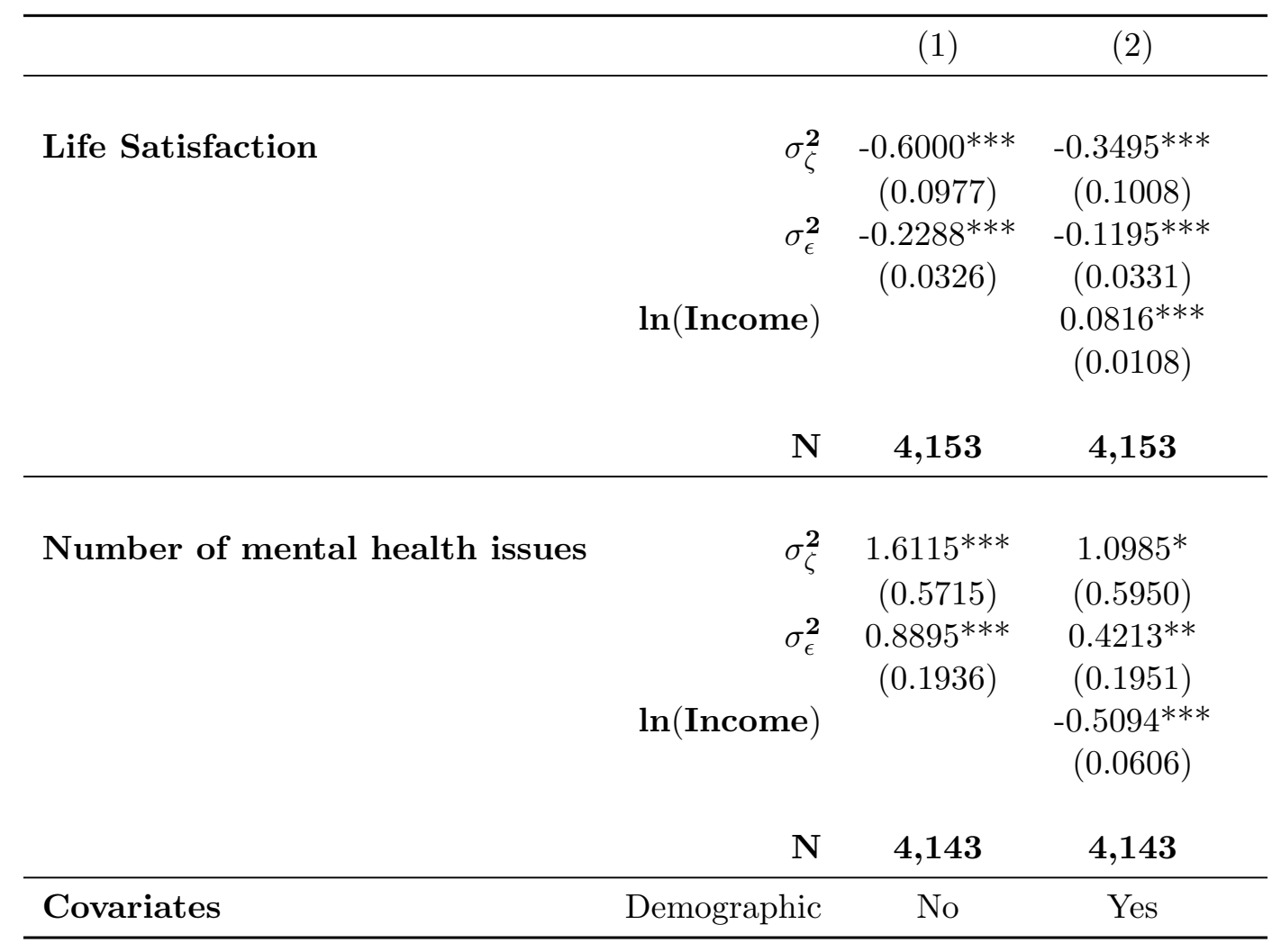

Table 4 (continued): Effect of income volatility on health and well-being 


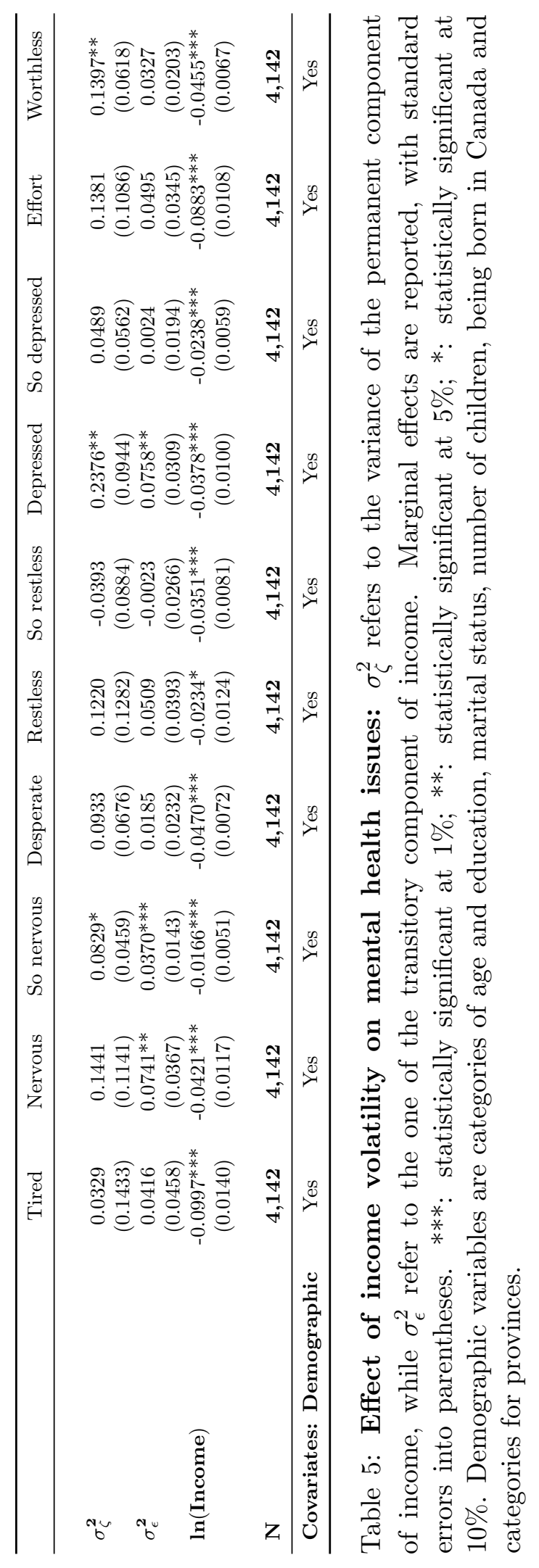




\subsection{Robustness}

We investigate the association of income volatility on health and well-being outcomes using two additional sub-samples in order to extend the validity of our results (see columns (2) and (3) of Table 6) .

The first robustness test performed uses the variances for which we control for disability benefits an individual may have received. The idea is to correct for health shocks during the working life which may cause volatility in income. In column (2) of Table 6, results for the variances of both permanent and transitory components of income are very similar to the baseline estimates (column (1)). For instance, a one unit increase in the variance of the permanent component of income is associated with a $23.59 \%$ decrease in the probability to report being in excellent health (compared to a $23.86 \%$ decrease in the baseline results), a $35 \%$ decrease in the probability to report being satisfied with life (compared to a $34.95 \%$ decrease in the baseline results), and increases by 1.13 the onset of mental health issues (compared to 1.1 in the baseline results, i.e. column (1)). As a result, when disability is used to compute income variances, we purge the latter from health effects and come closer to measures of the variances which are orthogonal to health shocks. Results are very similar to the baseline ones. One possibility is that volatility of income is caused by changes in household composition. The second robustness test performed considers a sample with a control over the number of different relationships that an individual had (column (3)). When the variances of the permanent and transitory components of income are estimated, even if a person reports being in a relationship for two years in a row, this individual may have been in a relationship with different people who earned different annual incomes. We thus control for the different relationship in order to capture such effects. Results for all outcomes are qualitatively similar (and even smaller in magnitude for the permanent component of income) when compared to the baseline estimates (column (1)). The variance of the permanent component of income has a negative association with probabilities to be in excellent and very good health, on the probability to report being satisfied with life, and increases the number of mental health issues. Specifically, a one unit increase in the latter is associated with a $23.19 \%$ decrease in 
the probability to report being in excellent health, a $34.67 \%$ decrease in the probability to report being satisfied with life, and increases the number of mental health issues by 1.07. Similarly, results for the variance of the transitory component of income are qualitatively similar to the baseline results. 


\section{Conclusion}

In this paper, we test the hypothesis that income volatility is associated with worse health outcomes and well-being. Using the Longitudinal and International Study of Adults (LISA) and its associated retrospective component for administrative data which follow Canadians, we investigate whether a relationship exists between health and well-being on the one hand and individual-specific volatility of income on the other, decomposing volatility into permanent and transitory components.

Our results suggest that permanent and transitory income volatility are associated with a deterioration of health and well-being, which is consistent with the theory of allostatic load (Seeman et al. (1997)). A one unit increase in the variance of the permanent component of income experienced over the working life is associated with a decrease the probabilities to be in excellent and very good health by $23.86 \%$ and $13.31 \%$ respectively, decreases the probability to be satisfied with life by $34.95 \%$, and is associated with the onset of 1.1 additional mental health issues. Moreover, a one unit increase in the variance of the transitory component of income is associated with a decrease of the probabilities to be in excellent and very good health by $5.74 \%$ and $3.20 \%$ respectively; decreases the probability to be satisfied with life by $11.95 \%$, and increases the number of mental health issues by 0.42 . These results are robust to the inclusion of controls for disability during the working life, an attempt to account for reverse causality. They also hold if we control for the composition of the household. In other words, this association is not due to changes in household composition over the life-cycle.

Establishing causality between income volatility and health outcomes is a difficult endeavor. Despite our best efforts to control for other life-time factors, including disability, it is possible that causality runs the other way: individuals who are more fragile in terms of both physical and mental health incur more income shocks. Our results are however consistent with a mounting body of work which shows that labor market shocks have a causal impact on health outcomes (Strully (2009); Sullivan \& Von Wachter (2009); Michaud et al. (2016); Schaller \& Stevens (2015)). Finally, understanding this potential relationship has important 


\begin{tabular}{|c|c|c|c|c|c|}
\hline & & & (1) & (2) & (3) \\
\hline \multirow[t]{16}{*}{ Self Assessed Health } & $\sigma_{\zeta}^{2}$ & Excellent & $\begin{array}{c}-0.2386^{* * *} \\
(0.0787)\end{array}$ & $\begin{array}{c}-0.2359 * * * \\
(0.0788)\end{array}$ & $\begin{array}{c}-0.2319^{* * *} \\
(0.0813)\end{array}$ \\
\hline & & Very good & $\begin{array}{c}-0.1331^{* * *} \\
(0.0440)\end{array}$ & $\begin{array}{c}-0.1316^{* * *} \\
(0.0440)\end{array}$ & $\begin{array}{c}-0.1287^{* * *} \\
(0.0452)\end{array}$ \\
\hline & & Good & $\begin{array}{c}0.1592^{* * *} \\
(0.0526)\end{array}$ & $\begin{array}{c}0.1575^{* * *} \\
(0.0526)\end{array}$ & $\begin{array}{c}0.1581^{* * *} \\
(0.0554)\end{array}$ \\
\hline & & Fair & $\begin{array}{c}0.1317^{* * *} \\
(0.0436)\end{array}$ & $\begin{array}{c}0.1302^{* * *} \\
(0.0436)\end{array}$ & $\begin{array}{c}0.1266^{* * *} \\
(0.0445)\end{array}$ \\
\hline & & Poor & $\begin{array}{c}0.0808^{* * *} \\
(0.0270)\end{array}$ & $\begin{array}{c}0.0799^{* * *} \\
(0.0270)\end{array}$ & $\begin{array}{c}0.0760^{* * *} \\
(0.0270)\end{array}$ \\
\hline & $\sigma_{\epsilon}^{2}$ & Excellent & $\begin{array}{c}-0.0574^{* *} \\
(0.0258)\end{array}$ & $\begin{array}{c}-0.0584^{* *} \\
(0.0257)\end{array}$ & $\begin{array}{c}-0.0634^{* *} \\
(0.0272)\end{array}$ \\
\hline & & Very good & $\begin{array}{c}-0.0320^{* *} \\
(0.0144)\end{array}$ & $\begin{array}{c}-0.0326^{* *} \\
(0.0144)\end{array}$ & $\begin{array}{c}-0.0352^{* *} \\
(0.0151)\end{array}$ \\
\hline & & Good & $\begin{array}{c}0.0383^{* *} \\
(0.0172)\end{array}$ & $\begin{array}{c}0.0390^{* *} \\
(0.0172)\end{array}$ & $\begin{array}{c}0.0432^{* *} \\
(0.0185)\end{array}$ \\
\hline & & Fair & $\begin{array}{c}0.0317^{* *} \\
(0.0143)\end{array}$ & $\begin{array}{c}0.0322^{* *} \\
(0.0142)\end{array}$ & $\begin{array}{c}0.0346^{* *} \\
(0.0149)\end{array}$ \\
\hline & & Poor & $\begin{array}{c}0.0194^{* *} \\
(0.0088)\end{array}$ & $\begin{array}{c}0.0198^{* *} \\
(0.0088)\end{array}$ & $\begin{array}{c}0.0208^{* *} \\
(0.0090)\end{array}$ \\
\hline & $\ln ($ Income $)$ & Excellent & $\begin{array}{c}0.0817^{* * *} \\
(0.0082)\end{array}$ & $\begin{array}{c}0.0817^{* * *} \\
(0.0082)\end{array}$ & $\begin{array}{c}0.0807^{* * *} \\
(0.0086)\end{array}$ \\
\hline & & Very good & $\begin{array}{c}0.0456^{* * *} \\
(0.0047)\end{array}$ & $\begin{array}{c}0.0456^{* * *} \\
(0.0047)\end{array}$ & $\begin{array}{c}0.0448^{* * *} \\
(0.0049)\end{array}$ \\
\hline & & Good & $\begin{array}{c}-0.0546^{* * *} \\
(0.0055)\end{array}$ & $\begin{array}{c}-0.0545^{* * *} \\
(0.0055)\end{array}$ & $\begin{array}{c}-0.0550^{* * *} \\
(0.0059)\end{array}$ \\
\hline & & Fair & $\begin{array}{c}-0.0451^{* * *} \\
(0.0047)\end{array}$ & $\begin{array}{c}-0.0451^{* * *} \\
(0.0047)\end{array}$ & $\begin{array}{c}-0.0440^{* * *} \\
(0.0049)\end{array}$ \\
\hline & & Poor & $\begin{array}{c}-0.0277^{* * *} \\
(0.0032)\end{array}$ & $\begin{array}{c}-0.0277^{* * *} \\
(0.0032)\end{array}$ & $\begin{array}{c}-0.0265^{* * *} \\
(0.0032)\end{array}$ \\
\hline & & $\mathbf{N}$ & 4,890 & 4,889 & 4,678 \\
\hline Covariates & & Demographic & Yes & Yes & Yes \\
\hline
\end{tabular}

Table 6: Robustness tests - Marginal effects are reported. Standard errors into parentheses. ${ }^{* * *}$ : statistically significant at $1 \% ; * *$ : statistically significant at $5 \%$; ${ }^{*}$ : statistically significant at $10 \%$. Demographic variables are categories of age and education, marital status, number of children, being born in Canada and categories for provinces. Self-assessed health is clustered at the respondent level. 


\begin{tabular}{|c|c|c|c|c|}
\hline & & (1) & $(2)$ & $(3)$ \\
\hline \multirow[t]{6}{*}{ Life Satisfaction } & $\sigma_{\zeta}^{2}$ & $-0.3495^{* * *}$ & $-0.3500 * * *$ & $-0.3467^{* * *}$ \\
\hline & $\sigma^{2}$ & $-01195 * * *$ & $-01223 * * *$ & $-0.1186 * * *$ \\
\hline & & $(0.0331)$ & $(0.0329)$ & $(0.0343)$ \\
\hline & $\ln ($ Income $)$ & $0.0816^{* * *}$ & $0.0814^{* * *}$ & $0.0782^{* * *}$ \\
\hline & & $(0.0108)$ & $(0.0108)$ & $(0.0110)$ \\
\hline & $\mathbf{N}$ & 4,153 & 4,153 & 3,987 \\
\hline \multirow[t]{7}{*}{ Number of Mental Health Issues } & $\sigma_{\zeta}^{2}$ & $1.0985^{*}$ & $1.1289^{*}$ & $1.0676^{* *}$ \\
\hline & & $(0.5950)$ & $(0.5955)$ & $(0.932)$ \\
\hline & $\sigma_{\epsilon}^{2}$ & $0.4213^{* *}$ & $0.4375^{* *}$ & $0.5731^{* *}$ \\
\hline & & $(0.1951)$ & $(0.1946)$ & $(0.305)$ \\
\hline & $\ln ($ Income $)$ & $-0.5094^{* * *}$ & $-0.5083^{* * *}$ & $-0.3396^{* * *}$ \\
\hline & & $(0.0606)$ & $(0.0606)$ & $(0.073)$ \\
\hline & $\mathbf{N}$ & 4,143 & 4,142 & 3,979 \\
\hline Covariates & Demographic & Yes & Yes & Yes \\
\hline
\end{tabular}

Table 6 (continued): Robustness tests 
implications for social policy. For example, if causal, this relationship would imply that social insurance improves health at older ages. Furthermore, it emphasizes that health policy may target both lower income individuals but also individuals who have significant variation in their incomes. 


\section{References}

Abowd, J. M. \& Card, D. (1989). On the covariance structure of earnings and hours changes. Econometrica, 57, 411-445.

Benitez-Silva, H., Buchinsky, M., Man Chan, H., Cheidvasser, S., \& Rust, J. (2004). How large is the bias in self-reported disability? Journal of Applied Econometrics, 19(6), 649670 .

Bound, J., Brown, C., \& Mathiowetz, N. (2001). Measurement error in survey data. In Handbook of econometrics, volume 5 (pp. 3705-3843). Elsevier.

Carroll, C. D. \& Samwick, A. A. (1997). The nature of precautionary wealth. Journal of Monetary Economics, 40(1), 41-71.

Case, A., Lubotsky, D., \& Paxson, C. (2002). Economic status and health in childhood: The origins of the gradient. American Economic Review, 92(5), 1308-1334.

Deaton, A. (2008). Income, health, and well-being around the world: Evidence from the gallup world poll. Journal of Economic Perspectives, 22(2), 53-72.

MaCurdy, T. E. (1982). The use of time series processes to model the error structure of earnings in a longitudinal data analysis. Journal of Econometrics, 18(1), 83-114.

Meghir, C. \& Pistaferri, L. (2004). Income Variance Dynamics and Heterogeneity. Econometrica, 72(1), 1-32.

Michaud, P.-C., Crimmins, E. M., \& Hurd, M. D. (2016). The effect of job loss on health: Evidence from biomarkers. Labour economics, 41, 194-203.

Moffitt, R. A. \& Gottschalk, P. (2011). Trends in the covariance structure of earnings in the US: 1969-1987. The Journal of Economic Inequality, 9(3), 439-459.

Schaller, J. \& Stevens, A. H. (2015). Short-run effects of job loss on health conditions, health insurance, and health care utilization. Journal of Health Economics, 43, 190-203.

Seeman, T. E., Singer, B. H., Rowe, J. W., Horwitz, R. I., \& McEwen, B. S. (1997). Price of adaptation-allostatic load and its health consequences. \{MacArthur\} studies of successful aging. Archives of internal medicine, 157(19), 2259-2268.

Smith, J. P. (1999). Healthy bodies and thick wallets: The dual relation between health and economic status. The Journal of Economic Perspectives : A Journal of the American Economic Association, 13(2), 144-166.

Smith, J. P. (2007). The Impact of Socioeconomic Status on Health over the Life-Course. Journal of Human Resources, XLII(4), 739-764.

Strully, K. W. (2009). Job loss and health in the US labor market. Demography, 46(2), 221-246. 
Sullivan, D. \& Von Wachter, T. (2009). Job displacement and mortality: An analysis using administrative data. The Quarterly Journal of Economics, 124(3), 1265-1306.

Winkelmann, L. \& Winkelmann, R. (1998). Why are the unemployed so unhappy? Evidence from panel data. Economica, 65(257), 1-15.

Winkleby, M. A., Jatulis, D. E., Frank, E., \& Fortmann, S. P. (1992). Socioeconomic status and health: how education, income, and occupation contribute to risk factors for cardiovascular disease. American journal of public health, 82(6), 816-820. 


\section{A Health variables}

1. Mental health - 2014: "In the last month, how often ("never", "rarely", "sometime", "most of the time", or "all the time") did you feel...":

(a) tired out for no good reason?

(b) nervous?

(c) so nervous that nothing could calm down?

(d) desperate?

(e) restless or be unable to stand still?

(f) so restless that could not stand still?

(g) sad/depressed?

(h) so depressed that nothing could cheer up?

(i) everything was an effort?

(j) good for nothing?

2. Life satisfaction - 2014: "What feelings do you currently have about your life in general: very unsatisfied (0) [...] very satisfied (10)?"

3. Self-assessed health - 2012/2014: "Would you say your health in general is...: excellent, very good, good, fair or poor ?";

\section{B Information window on income}

Note: a respondent who is 75 years old in 2012, was 45 years old in 1982 and 55 years old in 1992. We thus end up with 11 observations on his annual income. 


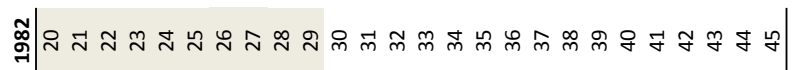
ఫ్య

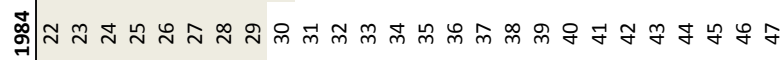
ఏ్య

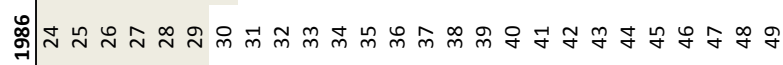
ఏ్య 包

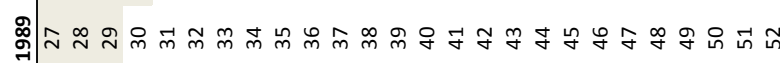

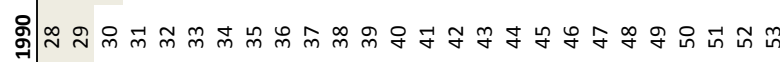

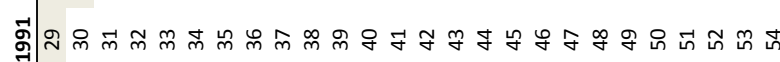

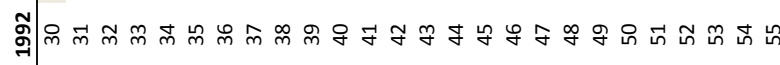

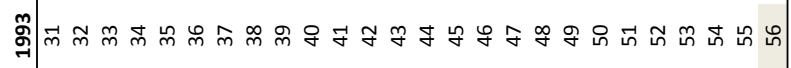
ఫ̆

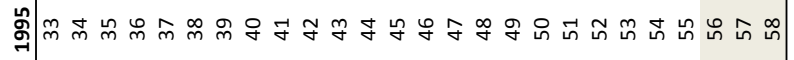

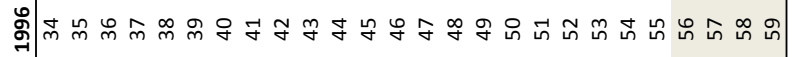

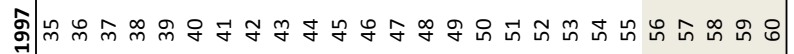
造

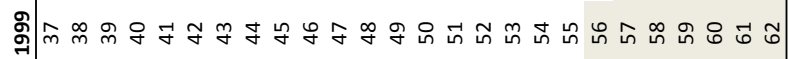

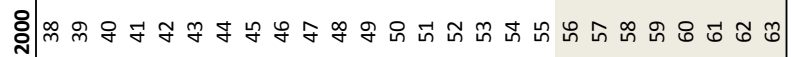

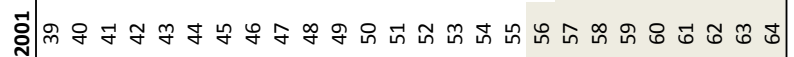

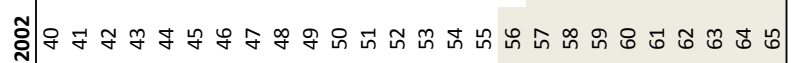

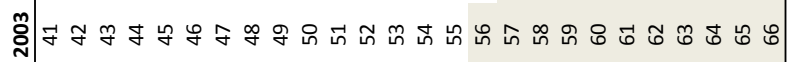

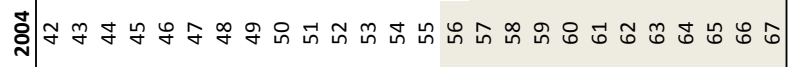

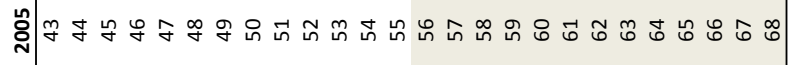

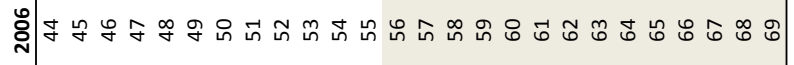

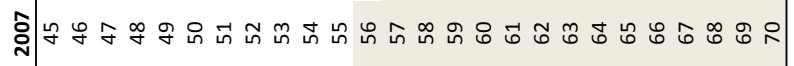

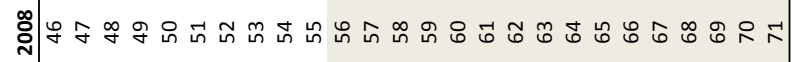

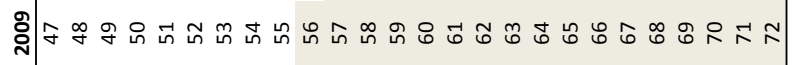

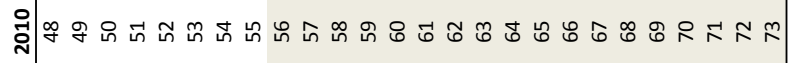

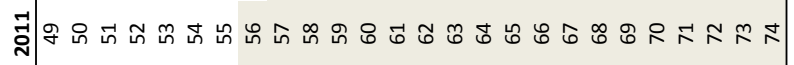

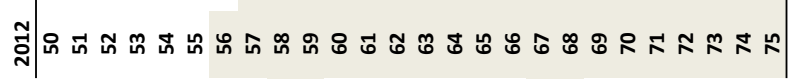

